\title{
Academic model of trauma healing in post-war societies
}

\author{
Amra Delić ${ }^{1}$, Mevludin Hasanovićn 2 Esmina Avdibegović ${ }^{2}$, Aleksandar Dimitrijevićs, \\ Camellia Hancheva ${ }^{4}$, Carmen Scher ${ }^{5}$, Tatjana Stefanović-Stanojević ${ }^{6}$, Annette Streeck- \\ Fischer $^{5}$, Andreas Hamburger ${ }^{5}$
}

${ }^{1}$ Health Centre Tuzla, Tuzla

Bosnia and Herzegovina

${ }^{2}$ Department of Psychiatry, University Clinical Hospital Tuzla, Tuzla, Bosnia and Herzegovina

${ }^{3}$ Faculty of Philosophy, University of Belgrade, Belgrade, Serbia

${ }^{4}$ Department of General, Experimental and Genetic Psychology, Sofia University

"St. Kliment Ohridski”, Bulgaria

${ }^{5}$ International Psychoanalytic University

Berlin, Berlin, Germany

${ }^{6}$ Faculty of Philosophy, University of Banja

Luka, Banja Luka, Bosnia and Herzegovina

Corresponding author:

Amra Delić

Health Centre Tuzla

Tuzla, Bosnia and Herzegovina

a.delic@bih.net.ba

Tel.: +38761666370

Fax.: + 38735268011

Received: 30 September 2013

Accepted: 16 January 2014

Copyright () 2014 by

Academy of Sciences and Arts

of Bosnia and Herzegovina.

E-mail for permission to publish:

amabih@anubih.ba
Objective. The aim of this paper is to examine the implications for healing in a contemporary Balkan post-war context, and to provide a bridge-building model of trauma transformation, reconciliation and recovery through academic reconstruction and cross-border dialogue. Post-war societies are marked by the effects of massive, large group traumatization, and if not properly dealt with, long-term rehabilitation and social recovery cannot be expected. Unprocessed cumulative trauma that has become deeply embedded in the collective memory of the Balkan peoples over centuries, „chosen trauma“, its trans-generational transmission and periodical reactivations across the Balkan have often been addressed in recent literature, in ethno-psychology, psychoanalysis, psychiatry, sociology and anthropology. In order to deepen our understanding of the roots of collective (social) trauma and the specific traumatic experiences of different groups, and to offer different perspectives and information on how trauma can be dealt with, the "Trauma Trust Memory" multinational interdisciplinary research network is being established, and a groundbreaking workshop was held in May 2013 in Tuzla, Bosnia-Herzegovina. Conclusion. The Tuzla Workshop showed that the active participation of affected groups in adequate coping with the past is required for post-conflict reconstruction, trauma healing and peacebuilding in the long run.

Key words: Post-war societies, Trauma healing, Academic reconstruction.

\section{Introduction}

The dissolution of the ex-Yugoslavia in the early 1990's was followed by the Slovenian, Croatian and Bosnia and Herzegovinian (BH) declarations of independence, which resulted in war (1991-1999) characterized by war crimes, crimes against humanity and genocide (1-3). Survivors report mass destruction, the prominence of ethno-nationalism, wide-scale violation of human rights, ethnic and political persecution, forced $\mathrm{mi}-$ 
grations, enslavement, concentration camps, mistreatment of prisoners, starvation, murder of the civilian population, mass rape, executions, and mass graves (1-4).

The wars in ex-Yugoslavia had dramatic consequences for all the republics of the former Yugoslavia, and more specifically $\mathrm{BH}$, where the most hostile actions and violent battles took place (3-4). The final figures on the horrendous atrocities committed during the war (1992-1995) in BH (1-4): 103,000 killed, of which $60 \%$ civilians, 30,000 missing persons, 170,000 wounded, over 20,000 raped, and over 2 million became refugees or displaced persons, most of them driven from their homes in pogroms of "ethnic cleansing".

With the aim of overcoming individual and social experiences of traumatization and to create the conditions for subjective and collective reconciliation and healing, through academic reconstruction and collaboration, a Stability Pact based the multinational research network - "Trauma, Trust and Memory" (TTM) - was founded in January 2013, in partnership with the German Academic Exchange Service (DAAD), connecting the interdisciplinary work of the International Psychoanalytic University (IPU) in Berlin to research centers on social trauma in $\mathrm{BH}$, Bulgaria, and Serbia. The transfer between clinical and cultural scientific expertise - through psychotherapy research, epidemiological studies, psychological studies of trauma experience and processing, studies on the cultural processing of collective trauma through literature and film analyses - is a specific feature of the TTM Network. The terms "academic-oriented trauma healing" and "academic reconstruction" are used in this paper. We define academic-oriented trauma healing as the process in which explanatory models of complex trauma processes and trauma effects on the next generation, as well as trans-generational trauma healing, should be developed through trauma research and facilitating discussion about trauma consequences, within multinational interdisciplinary groups of students, professors and practitioners. This paper uses the term academic reconstruction within the framework of the DAAD/TTM network program referring to: a) improving the quality of education and training in the field of social trauma offered at institutions of higher education in South Eastern Europe (SEE); b) establishing a teaching and research inter-institutional network with the aim of fostering cross-border co-operation; c) targeting support for young academically qualified experts from the region, while initiating joint research projects. Apart from the academic exchange of direct beneficiaries of this program (the network members and institutions), the students, lecturers and practitioners are motivated to share their knowledge and experience by taking part in a wide range of activities related to trauma transformation, reconciliation and peacebulding through local community outreach projects.

\section{Academic-oriented Trauma Healing - Our experience}

A social trauma is the consequence of traumatic events (i.e. war), which develop within the context of one's own group or community. Post-war societies in the Balkans are marked by the effects of massive large group traumatization that is multidimensional, and therefore we use an interdisciplinary approach to trauma healing. Our aim is to face history, and to make traumatic traces visible and addressable. We enhance dialogues on social trauma between psychiatry and psychoanalysis, psychology and history, clinical, conceptual, empirical qualitative and quantitative approaches, academic and therapeutic contexts as well as survivors' organizations, from different countries looking back to a long history full of atrocities. 
We come from different cultures, but we share similar aspirations, being inclined to a thorough understanding instead of quick judgments, to dialogue instead of quarrel, and to reflection instead of projection. If trauma causes the disintegration of linking processes within the psyche, such that overwhelming traumatic experiences cannot be integrated into an affect-connected longtime memory, but circulate like errant fighters in the jungle of a fragmented autobiography - then what helps is acknowledgement, respect, and connection by naming the truth. In our social histories there are also many fragmented discourses. The borders we are crossing through our network may be characterized by pointing to the history that marked some of us in the early nineties: the Yugoslav wars and the overthrowing of the Socialist Systems. The experiences, such as dictatorship, torture, war, rupture within families and neighborhoods, genocide, ethnic cleansing and mass rapes that took place in this region not so long ago are to be shared - the survivors are still alive and young, and some of the researchers connected in this cooperation are able to tell a personal story. The historical lines that cross here are highly interconnected with each other and with European, and especially German history. The network comprises research into the traumatic impact of dictatorial societies and war, be it in clinical or cultural studies. In the first six months of our joint work, the thematic and methodological fields of cooperation were identified and developed in workshops, fellow-trainings, and summer schools. In May 2013, a groundbreaking Workshop entitled: "Social Trauma, Trust and Collective Memory" on Complex Trauma, Group Identity and Reconciliation, was held in Tuzla, BH. The Workshop aimed at providing an overview of current trends in the areas of the complexity of adolescent and social trauma with its aftermath, and research and clinical practice in post- conflict countries, with the contribution of prominent experts in various fields. A keynote lecture on Complex Traumatization in Adolescents and a presentation about the ways in which social trauma caused extreme attitudes among young people in East Germany was given by the child and adolescent psychiatrist and psychoanalyst, Professor Annette Streeck-Fischer from IPU Berlin, now President of the International Society for Adolescent Psychiatry (ISAP). Various clinical illustrative presentations were given throughout the workshop.

Since the workshop schedule coincided with the $18^{\text {th }}$ Anniversary of the "Massacre of Tuzla Youth“, a documentary „Tonight, we will love for them" was presented in the workshop session Facing the Past - Transforming our Future. After that the participants remembered the victims at the Kapija Memorial. Also, the participants visited the association helping the victims and survivors of sexualized violence in war, "Our Voice," and the association for mutual assistance in mental distress "Fenix", to learn more about the importance of psychosocial intervention and social support for users' associations. On the last day of the workshop, within a session entitled We Can Make a Difference, the group visited the SrebrenicaPotocari Memorial and Cemetery for the Victims of the 1995 Genocide and paid tribute to the victims.

Presentations on "Group Identity and Reconciliation", "The Practical Application of Contact Theory in BH", and "The Link between Trauma, Conflict and Sustainable Peacebuilding" stimulated group discussions, where we collectively addressed the challenges of applying the "Trauma, Trust, and Memory" network, while facing the „traumatic traces of our history." In trying to understand better the roots of social trauma and the consequences of mass atrocities, we tackled the topics of large social group identity, narcissism of small differences, "chosen 
trauma", the phantasm of revenge, victim playing as a coping strategy, trans-generational trauma transmission, false history, and the "conspiracy of silence" around these issues (5-7). The workshop was thoroughly interactive, initiating science dialogue that spontaneously illustrated the beginning of trauma-transformation and peace building efforts focussing on building relationships and trust across the borders, which in our recent past represented conflict lines.

\section{Future directions}

In $\mathrm{BH}$ today, where we are still facing the continual fabrication of ethno-nationalism, the wide-spread denial of atrocities and impunity, initiating trauma transformation, the repair and restoration of relationships, rebuilding trust and strengthening reconciliation in a tense post-conflict arena is difficult, but hope-infusing and promising. From the perspective of our local contexts and situations, the TTM Workshop in Tuzla provided a real opportunity to transcend boundaries and build a learning collaborative of people from the academic societies of different countries in the region, who can work together to provide the crossborder cross-sector collaboration needed to support the achievement of the TTM Network objectives. It is not only a scientific exchange, but also the personal and the political bridges that are built through this cooperation. And, as we know from the feminist academic debates back in the sixties (8), "the personal is political" - since it has to do with human beings, even if it does not always seem so - and in reverse, the political is personal, since we live and grow in contexts. We can do something to improve them. Our working alliance in the TTM network is but one step. The Tuzla Workshop resulted in a wide spirit of collaboration and determination to continue the dialogue, especially among young scientists, research- ers, and clinicians. This will hopefully form part of a joint academic reconstruction project, which draws upon regional perspectives to deepen understanding of social trauma, reduce mistrust, and facilitate reconciliation and healing. Serving as a platform, where science, therapeutic and teaching practices, dialogue and empathy come together in healing the wounds of history, the DAAD supported "Trauma Trust Memory" project aroused and encouraged interest in cooperation and/or coordination of efforts with other academic sectors and agencies working in different areas: i.e., history, sociology, peacebuilding, journalism, and maintaining survivor organizations. This should magnify the impact for a broader peace, aiming at producing and strengthening significant personal transformations in attitudes, perception and trust, and translating these personal transformations into actions at the socio-political level (9).

\section{Conclusion}

Enhancing the "Trauma Trust Memory" research network, continual interdisciplinary networking, collaboration and friendship through high-level academic dialogue, training workshops, study visits and joint projects, should be a must in any future strategy of academic reconstruction and developments in post-conflict societies in the Balkans, and not only in the Balkans.

Authors' contributions: Conception and design: Am.D MH, Al.D, AH; Drafting the article Am.D, MH, EA, Al.D, AH; Revising it critically for important intellectual content: Am.D, MH, EA, Al.D, AH, CH, CS, TSS, ASF.

Conflict of interest: The authors declare that they have no conflict of interest.

\section{References}

1. Hasanović M. Psychological consequences of wartraumatized children and adolescents in Bosnia and Herzegovina. Acta Med Acad. 2011;40:45-66. 
2. Brennen T, Hasanović M, Zotović M, Blix I, Skar AM, Prelić NK, et al. Trauma exposure in childhood impairs the ability to recall specific autobiographical memories in late adolescence. J Trauma Stress. 2010;23:240-7.

3. Kravić N, Pajević I, Hasanović M. Surviving genocide in Srebrenica during the early childhood and adolescent personality. Croat Med J. 2013;54:55-64.

4. Hasanović M, Haračić E, Ahmetspahić Š, Kurtović S, Haračić H. Poverty and Psychological Disturbances of War-Traumatized Adolescents from $\mathrm{Ru}$ ral and Urban Areas in Bosnia and Herzegovina. In: Mallory E. Weinstein, editor. Encyclopedia of Psychology Research (2 Volume). New York: Nova Publishers; 2011. p. 863-88.

5. Volkan VD. Large-group psychodynamics and massive violence. Ciência \& Saúde Coletiva. 2006;11(2):303-14.
6. McKinney K. "Breaking the Conspiracy of Silence": Testimony, Traumatic Memory, and Psychotherapy with Survivors of Political Violence. Ethos. 2007;35(3):265-99.

7. Jakovljević M, Brajković L, Jakšić N, Lončar M, Aukst-Margetić B, Lasić D. Posttraumatic stress disorder (PTSD) from different perspectives: a transdiciplinary integrative approach. Psychiatr Danub. 2012;24(3):246-55.

8. Hanisch C. The Personal Is Political. In: Firestone S, Koedt A, editors. Notes from the Second Year: Women's Liberation; Major Writings of the Radical Feminists. New York: Radical Feminism; 1970.

9. U.S. Agency for International Development; USAID Office of Conflict management and Mitigation. People - to - People Peacebuilding: A Program Guide. Washington, DC: USAID; 2011. 